\title{
Anthraquinones from the saline-alkali plant endophytic fungus Eurotium rubrum
}

\author{
Yonggang Zhang ${ }^{1,2}$, Airong Jia ${ }^{2}$, Huabin Chen ${ }^{1,2}$, Menghua Wang ${ }^{3}$, Gang Ding ${ }^{3}$, Liyan Sun ${ }^{4}, \mathrm{Li} \mathrm{Li}^{5}$ \\ and Meixue Dai ${ }^{1}$
}

The Journal of Antibiotics (2017) 70, 1138-1141; doi:10.1038/ja.2017.121; published online 11 October 2017

\begin{abstract}
Saline-alkali plant endophytes similar as marine mangrove plantderived ones are a big member of microbes inhabiting in tissues of plants without causing obvious disease to their hosts, and they must adapt to the extreme environment of high osmolarity and nutrient deprivation in plant, which are different from terrestrial plant endophytes. Owing to the unique bio-environments, endophytes originated from mangrove plants are being considered as a new resource of natural product research and diverse secondary metabolites with a wide range of bioactivities have been isolated. ${ }^{1-3}$ Compared with those of marine mangrove plant-derived endophytes, chemical investigation of saline-alkali plant-derived endophytic fungi have just begun, and only several natural products were isolated from these unique environmental fungi. ${ }^{4-7}$ Suaeda salsa $L$., an important model halophytic plant, is distributed at different saline-alkali soil especially at seaside. This plant possesses the ability to absorb salt from saline soils and accumulate them in the plant tissues. Some results revealed that the total salt contents in shoot and root were $23-27 \%$ and $10-12 \%$, respectively. ${ }^{8}$ During our ongoing chemical investigation from unique fungal species as sources of new bioactive natural products, a halo-tolerant endophytic fungus Eurotium rubrum isolated from salt-tolerance wild plant S. salsa L. collected from 'BoHai' seaside was chosen to chemical investigation. Previous reports revealed that E. rubrumwas frequently isolated from mangrove plants, and different secondary metabolites with a wide range of bioactivities have been isolated from this endophytic fungus. ${ }^{9-13}$ Purification of the solid culture extract of this fungus led to isolate a new anthraquinone named rubrumol (1) with poly-hydroxyl groups together with four known analogs catenarin (2), ${ }^{14}$ rubrocristin $(3),{ }^{15}$ emodin $(4)^{16}$ and 2-methyleurotinone (5). ${ }^{15}$ In this paper, the structural elucidation for the new compound rubrumol (1) (Figure 1) and bioactivities for compounds $\mathbf{1 - 5}$ were present. Several errors on the coupling constants of the known coniothyrinone A (6) were pointed out in this note. ${ }^{17}$
\end{abstract}

The molecular formula of rubrumol (1) was determined to be $\mathrm{C}_{15} \mathrm{H}_{16} \mathrm{O}_{5}$ (8 degrees of unsaturation) on the basis of HRESIMS analysis $\left(\mathrm{m} / z 299.0889[\mathrm{M}+\mathrm{Na}]^{+} ; \Delta-0.1 \mathrm{mmu}\right)$. Analysis of the ${ }^{1} \mathrm{H},{ }^{13} \mathrm{C}$ and HMQC NMR data of $\mathbf{1}$ (Table 1) revealed the presence of four exchangeable proton (in which one hydroxyl group might form one intramolecular hydrogen-bond on account of its chemical shift value at $\delta_{\mathrm{H}} 11.82$ p.p.m.), one methyl group connected with double bond or phenyl ring ( $\delta_{\mathrm{H}} 2.33$ p.p.m.), five methines (three oxygenated), eight olefinic or aromatic carbons (4 of which are protonated) and one keto group carbon $\left(\delta_{\mathrm{C}} 205.2\right.$ p.p.m.). These data accounted for all the ${ }^{1} \mathrm{H}$ and ${ }^{13} \mathrm{C}$ NMR resonances and required $\mathbf{1}$ to contain three rings. Interpretation of the ${ }^{1} \mathrm{H}-{ }^{1} \mathrm{H}$ COSY NMR data of $\mathbf{1}$ identified one isolated proton spin-systems corresponding to the $\mathrm{C}-10$ (10-OH)-C-10a-C-5-C-6-C-7 (7-OH)-C-8(8-OH)-C-8a-C-10a fragment (Figure 1), which formed one cyclohexene ring (C ring). Owing to the effect of double bond and aromatic ring, the weak allylic even homoallylic coupling relationships were observed in the ${ }^{1} \mathrm{H}-{ }^{1} \mathrm{H}$ COSY NMR spectra, such as the cross peaks of 3-Me with $\mathrm{H}-2$ and $\mathrm{H}-4$, of $\mathrm{H}-4$ with $\mathrm{H}-10$, of $\mathrm{H}-5$ with $\mathrm{H}-7$, of $\mathrm{H}-6$ with $\mathrm{H}-10 \mathrm{a}$ (allylic coupling relationship) and of $\mathrm{H}-7$ with $\mathrm{H}-10 \mathrm{a}$ (homoallylic coupling relationship), which made the ${ }^{1} \mathrm{H}$ NMR spectrum more complex. The remaining connection was established by HMBC correlations (Figure 1). The hydroxyl group $\left(\delta_{\mathrm{H}} 11.82\right.$ p.p.m.) was attached at $\mathrm{C}-1$ due to the correlations of 1-OH with C-1, C-2 and C-9a, whereas the 3-methyl unit was connected with C-3 by its correlations with C-2, $\mathrm{C}-3$ and C-4. The correlations from $\mathrm{H}-2$ to C-1, C-4 and 3-Me and from H-4 to C-2, C-4a and C-9a revealed the existence of one 1,3,5,6tetra-substituted aromatic ring (A ring) with one hydroxyl group and one methyl unit anchored at C-1 and C-3, respectively. The $W$-type long ranged correlation from $\mathrm{H}-2$ and $\mathrm{H}-4$ to $\mathrm{C}-9$ displayed that C-9 was connected with C-9a, and this was consistent with the formation of the intramolecular hydrogen-bond by the keto group (C-9) with

${ }^{1}$ College of Life Sciences, Shandong Normal University, Jinan, China; ${ }^{2}$ Biology Institute of Shandong Academy of Sciences, Jinan, China; ${ }^{3}$ Key Laboratory of Bioactive Substances and Resources Utilization of Chinese Herbal Medicine, Ministry of Education, Institute of Medicinal Plant Development, Chinese Academy of Medical Sciences and Peking Union Medical College, Beijing, China; ${ }^{4}$ School of Pharmaceutical Science, Taishan Medical University, Taian, China and ${ }^{5}$ State Key Laboratory of Bioactive Substance and Function of Natural Medicines, Institute of Materia Medica, Beijing, China

Correspondence: Dr G Ding, Key Laboratory of Bioactive Substances and Resources Utilization of Chinese Herbal Medicine, Ministry of Education, Institute of Medicinal Plant Development, Chinese Academy of Medical Sciences and Peking Union Medical College, Beijing 100193, China.

E-mail: gding@implad.ac.cn

or Professor M Dai, College of Life Sciences, Shandong Normal University, Jinan 250014, China.

E-mail: daimeixue@sdnu.ac.cn

Received 14 June 2017; revised 30 August 2017; accepted 4 September 2017; published online 11 October 2017 

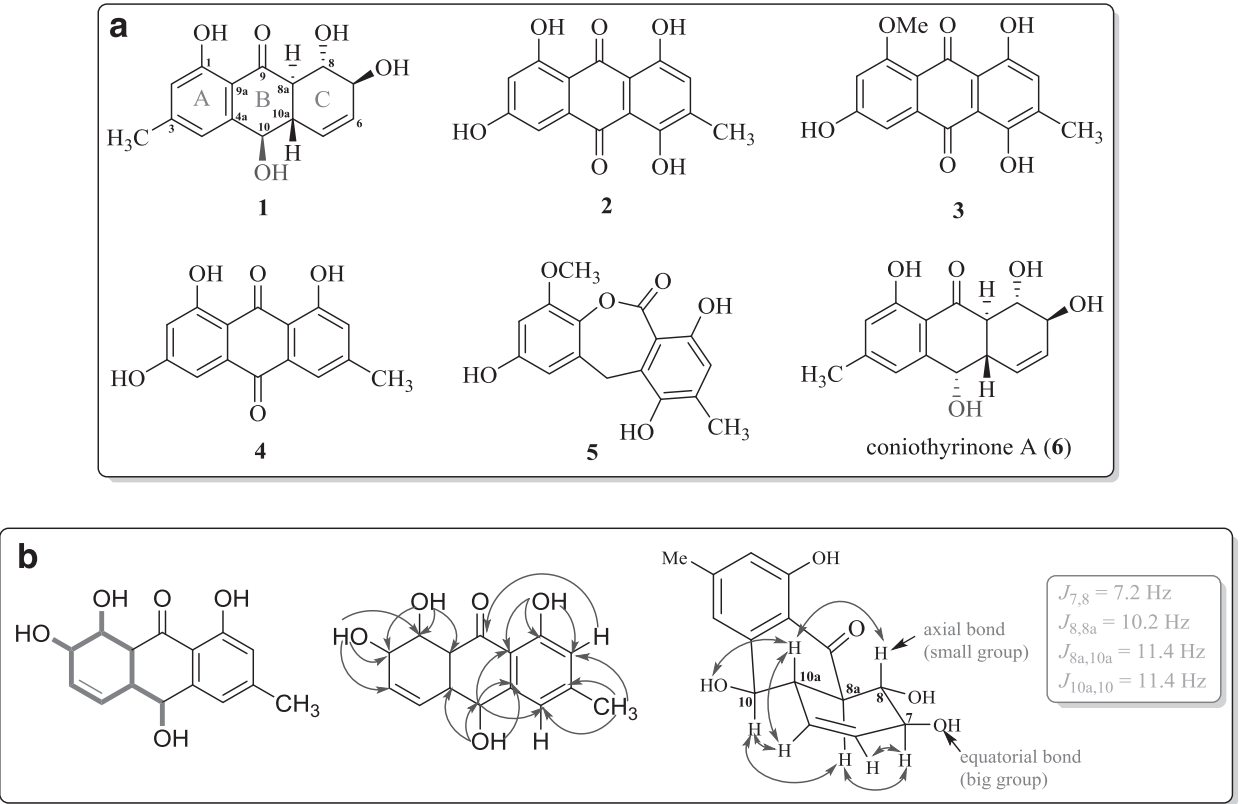

Figure 1 (a) Structures of compounds 1-6; (b) 2D NMR of 1. A full color version of this figure is available at The Journal of Antibiotics journal online.

1-OH leading to the downfield chemical shift value of the hydroxyl group proton ( $\delta_{\mathrm{H}} 11.82$ p.p.m.). The cross peaks of $\mathrm{H}-10$ with $\mathrm{C}-4$, C-9a, of $\mathrm{H}-4$ with $\mathrm{C}-10$ and especially of $10-\mathrm{OH}$ with $\mathrm{C}-4 \mathrm{a}$ in the HMBC spectra confirmed that C-4a was connected with C-10. The correlations from H-8 and H-8a to C-9 confirmed that the keto group (C-9) was connected with C-8a. Thus the planar structure for compound 1 was determined, which revealed the same planar structure as that of coniothyrinone A (6). ${ }^{17}$ Yet, the significant

Table 1 Comparison of NMR data between 1 and 6 (in DMSO- $d_{6}$ )

\begin{tabular}{|c|c|c|c|c|}
\hline \multirow[b]{2}{*}{ No. } & \multicolumn{2}{|c|}{ Compound (1) } & \multicolumn{2}{|c|}{ Coniothyrinone $A(6)$} \\
\hline & $\delta_{H^{a}},(\mathrm{~J}$ in $H z)$ & $\delta_{C}^{b}$, type & $\delta_{H^{a}},(\mathrm{~J}$ in $H z)$ & $\delta_{C}^{b}$, type \\
\hline 1 & & 160.2 & & $163.3, \mathrm{~s}$ \\
\hline 2 & $6.69, \mathrm{~s}$ & $115.1, \mathrm{CH}$ & $6.73, \mathrm{~s}$ & 118.3, d \\
\hline 3 & & 147.2 & & $150.0, \mathrm{~s}$ \\
\hline 4 & $7.03, \mathrm{~s}$ & $117.8, \mathrm{CH}$ & $6.80, \mathrm{~s}$ & $122.6, \mathrm{~d}$ \\
\hline $4 a$ & & 148.1 & & $146.2, \mathrm{~s}$ \\
\hline 5 & $5.94, \mathrm{dd}(2.4,10.2)$ & $125.0, \mathrm{CH}$ & $5.67, \mathrm{~s}$ & $128.8, \mathrm{~d}$ \\
\hline 6 & $5.61, \mathrm{dd}(2.4,10.2)$ & $130.4, \mathrm{CH}$ & $5.67, \mathrm{~s}$ & $132.1, \mathrm{~d}$ \\
\hline 7 & $4.00, \mathrm{~m}$ & $71.0, \mathrm{CH}$ & 4.18 , br.s & $73.6, \mathrm{~d}$ \\
\hline 8 & $\begin{array}{c}3.86, \text { ddd }(1.8,7.2 \\
10.2)\end{array}$ & $71.2, \mathrm{CH}$ & $\begin{array}{c}\text { 4.05, dd (10.3, } \\
3.0)\end{array}$ & $74.5, d$ \\
\hline $8 a$ & $2.78, \mathrm{dd}(10.2,11.4)$ & $49.4, \mathrm{CH}$ & $\begin{array}{c}\text { 3.29, dd }(10.3, \\
9.2)\end{array}$ & $45.6, d$ \\
\hline 9 & & 205.2 & & $208.8, \mathrm{~s}$ \\
\hline $9 a$ & & 112.8 & & $113.9, \mathrm{~s}$ \\
\hline 10 & $4.41, \mathrm{dd}(8.4,11.4)$ & 69.6, $\mathrm{CH}$ & 4.85 , br.s & $69.3, \mathrm{~d}$ \\
\hline $10 a$ & 2.57, br. t (11.4) & $44.8, \mathrm{CH}$ & 2.97 , dt $(9.2,2.6)$ & $44.2, d$ \\
\hline 3-Me & $2.33, \mathrm{~s}$ & $21.1, \mathrm{CH}_{3}$ & $2.34, \mathrm{~s}$ & $22.0, \mathrm{CH}_{3}$ \\
\hline $1-\mathrm{OH}$ & $11.82, \mathrm{~s}$ & & $11.89, \mathrm{~s}$ & \\
\hline $7-\mathrm{OH}$ & $5.12, \mathrm{~d}(6.0)$ & & $4.12, \mathrm{~s}$ & \\
\hline 8-OH & $4.86, \mathrm{~d}(1.8)$ & & $4.72, \mathrm{~s}$ & \\
\hline $10-\mathrm{OH}$ & $5.96, d(8.4)$ & & $4.56, \mathrm{~s}$ & \\
\hline
\end{tabular}

difference of ${ }^{1} \mathrm{H}$ NMR spectrum (in DMSO- $d_{6}$ ) especially the coupling constants suggested their differently relative configuration.

Coupling constants analysis to determine the relative configurations was often used in structural elucidation of natural products. The large coupling constants between $\mathrm{H}-10$ and $\mathrm{H}-10 \mathrm{a}(J=11.4 \mathrm{~Hz})$, between $\mathrm{H}-10 \mathrm{a}$ and $\mathrm{H}-8 \mathrm{a}(J=11.4 \mathrm{~Hz})$, between $\mathrm{H}-8 \mathrm{a}$ and $\mathrm{H}-8(J=10.2 \mathrm{~Hz})$ and between $\mathrm{H}-8$ and $\mathrm{H}-7(\mathrm{~J}=7.2 \mathrm{~Hz})$, implied that $\mathrm{H}-7, \mathrm{H}-8 \mathrm{a}$ and $\mathrm{H}-10$ were on the same side of $\mathrm{C}$ ring, whereas $\mathrm{H}-8$ and $\mathrm{H}-10 \mathrm{a}$ possessed the opposite orientation on the other of $\mathrm{C}$ ring. This information implied that the small groups such as $\mathrm{H}-7, \mathrm{H}-8, \mathrm{H}-8 \mathrm{a}$, $\mathrm{H}-10 \mathrm{a}$ and $\mathrm{H}-10$ were placed on the axial bonds, whereas the big groups $7-\mathrm{OH}, 8-\mathrm{OH}$ and $10-\mathrm{OH}$ were placed on equatorial bonds, which demonstrated the trans-annulation of $\mathrm{B}$ and $\mathrm{C}$ rings. The relative configuration of 1 was further confirmed by NOESY correlation from $\mathrm{H}-8 \mathrm{a}$ to $\mathrm{H}-7$ and $\mathrm{H}-10$ and from $\mathrm{H}-10 \mathrm{a}$ to $\mathrm{H}-8$ and $10-\mathrm{OH}$ (Figure 1). Thus the relative configuration for $\mathbf{1}$ was determined. Modified Mosher's reaction was tried to determine the absolute configuration of $1,{ }^{18}$ but several products were formed during the reaction, which made it very difficult to isolate the target products with limited amount and impurity.

Electronic circular dichroism has been recognized as a rapid and reliable method to assign absolute configuration of chiral molecules, especially, with the aid of quantum-chemical calculation using timedependent density functional theory, and electronic circular dichroism method has been widely applied in recent years. ${ }^{19-21}$ The MMFF94 conformational analysis of $\mathbf{1}$ only gave two conformers, which differs only in the orientation of hydrogen atoms and the hydroxyl groups. Further optimization in the density functional theory framework verified the existence of two conformers, and the privileged conformer coincided with the NMR data. As indicated in Supplementary Figure S7, the predicted electronic circular dichroism spectra of the $(7 S, 8 S, 8 \mathrm{a} R, 10 R, 10 \mathrm{a} S)$-enantiomer were in good match with the experimental data between 200 and $400 \mathrm{~nm}$. Therefore, the absolute configuration of compound 1 was established as $(7 S, 8 S, 8 \mathrm{a} R, 10 R, 10 \mathrm{a} S)$.

When analyzing the relative configuration of $\mathbf{1}$ and $\mathbf{6}$, we found that there were several errors about the coupling constants of 

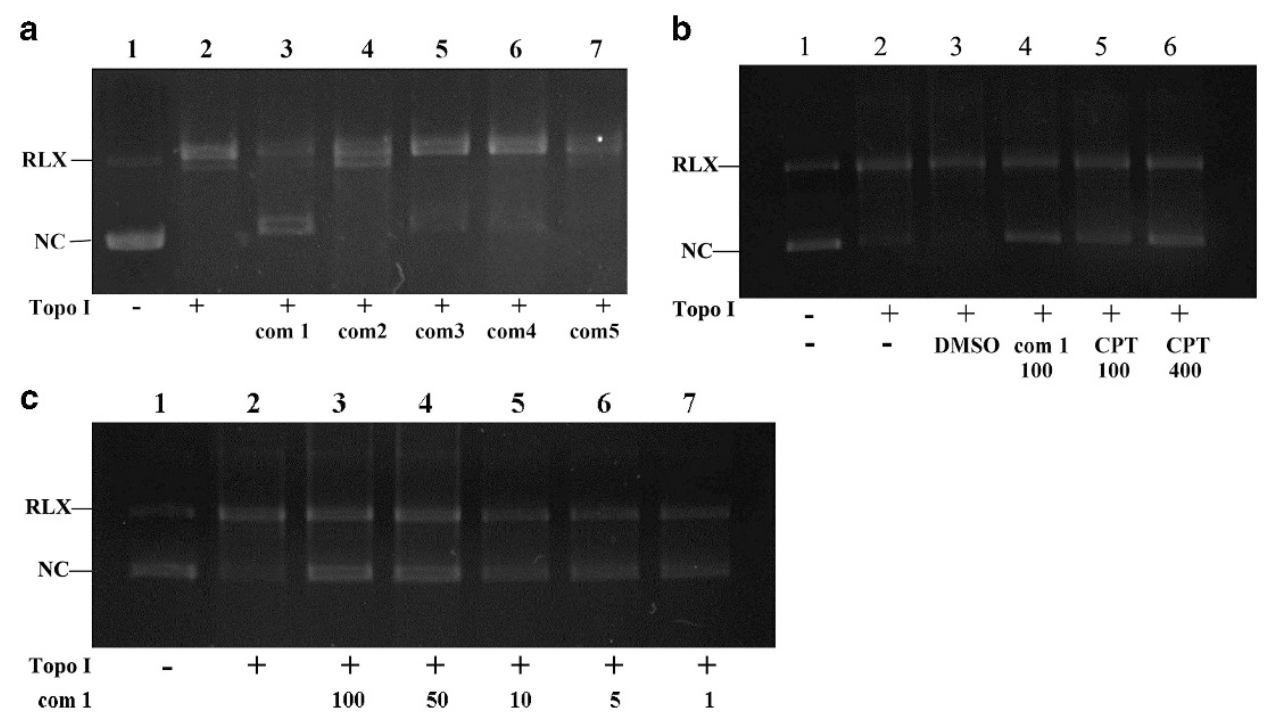

Figure 2 Effect of compound $\mathbf{1}$ and its analogs $\mathbf{2 - 5}$ on the relaxation activity of topoisomerase I (Topo I). (a) Effect of compounds $\mathbf{1 - 5}$ on the ability of Topo I to relax supercoiled pBR322 DNA (100 $\mu \mathrm{m})$. Lane 1, pBR322 DNA (no Topo I, no compound); Lane 2, Topo I (no compound); Lanes 3-7, compounds 1-5, respectively. (b) Effect of compound $\mathbf{1}$ on the ability of Topo I to relax supercoiled pBR322 DNA compared with camptothecin (CPT). Lane 1, pBR322 DNA (no Topo I, no compound); Lane 2, Topo I (no compound); Lane 3, Topo I+DMSO (no compound); Lanes 4, compound 1 with concentration of 100 Mm; Lanes 5-6, CPT with concentration of $100 \mu \mathrm{m}, 400 \mu \mathrm{m}$, respectively. (c) Effect of compound 1 on the plasmid DNA. Lane 1, pBR322 DNA (no Topo I, no compound); Lane 2, Topo I (no compound); Lanes 3-6, compound 1 with concentration of 100,50, 10, 5 and $1 \mu \mathrm{m}$, respectively.

coniothyrinone A (6). The coupling constant of $\mathrm{H}-7$ and $\mathrm{H}-8$ in 6 was $3.0 \mathrm{~Hz}$ (Supplementary Figure S8), implying that both these two protons should possess equatorial bonds, whereas the authors placed these two protons on the axial positions. In theory, the coupling constant between axial-axial protons are $6.0-8.0 \mathrm{~Hz}$, and the coupling constant between equatorial-equatorial protons are $2.0-4.0 \mathrm{~Hz}$. In addition, if the $\mathrm{H}-7$ was put on the equatorial bond, the NOESY correlation between $\mathrm{H}-7$ and $\mathrm{H}-8 \mathrm{a}$ could not be observed. Yet there was NOESY correlation between those two protons in the paper. This implied that the coupling constant of $\mathrm{H}-7$ and $\mathrm{H}-8(J=3.0 \mathrm{~Hz})$ was not right. All the discrepancies in the paper by Sun et al. ${ }^{17}$ might have originated from the bad quality of ${ }^{1} \mathrm{H}$ NMR spectrum, in which so many broad singlet or multiplets interfered the authors to correctly analyze the coupling constants of structure 6 .

The biological effect of rubrumol (1) and its derivatives $\mathbf{2 - 5}$ on Topo I to relax supercoiled pBR322 DNA were investigated in the cleavable complex assay (Figure 2). The results presented in Figure 2a indicated that only compound $\mathbf{1}$ displayed biological activity compared with the positive control camptothecin. As shown in Figure 2b, the relaxation activity of rubrumol (1) was stronger than that of camptothecin at the concentration $(100 \mu \mathrm{M})$. Furthermore, the decreasing concentrations of $\mathbf{1}$ were tested about the effect on relaxation activity (Figure $2 \mathrm{c}$ ), and the $\mathrm{IC}_{50}$ value of the inhibition of Topo I relaxation activity was $23 \mu \mathrm{M}$ (lane 1 ). The band backward shifting and trailing ofrubrumol (1) was observed in lanes 3-6 at 100, $50,10,5$ and $1 \mu \mathrm{M}$. The mechanism of action of rubrumol (1) on DNA was under ongoing. Rubrumol (1) was also assessed for cytotoxic activities against A549, MDA-MB-231, PANC-1 and HepG2 human cancer cell lines by the MTT (3-(4,5-dimethylthiazol-2-yl)2,5-diphenyltetrazolium bromide) method. The inhibition rate for 1 against these 4 cancer cell line were $<60 \%$ at $100 \mu \mathrm{g} \mathrm{ml}^{-1}$, which implied that 1 displayed no significant cytotoxic activities. Compounds 2-5 were also tested cytotoxicity against A549, MDAMB-231, PANC-1 and HepG2 human cancer cell lines by the MTT method without bioactivity.
Anthraquinones are one big member of secondary metabolites biosynthesized by polyketide pathway. There are some reports about hydroanthroqiunones, such as fusaranthraquinone, ${ }^{22}$ tetrahydroaltersolanols $\mathrm{C}-\mathrm{F},{ }^{23}$ dihydroaltersolanol $\mathrm{A},{ }^{24}$ 4a-epi-9 $\alpha$ methoxydihydrodeoxybostrycin ${ }^{24}$ and 10 -deoxybostrycin, ${ }^{24}$ most of which were hydrogenated in the C-ring. Anthraquinones displayed a wide range of bioactivities such as antibacterial, antifungal, antimycobacterial, antimalarial and cytotoxic activities, ${ }^{1-3,22-24}$ while there was no report about anthraquinones against topoisomerase I inhibitory activity. Though our work cannot explain the detailed ecological role of E. rubrum and interaction of the endophytic fungus with its host $S$. salsa $L$., the result in our experiment diversified the chemical structure of anthraquinones and also first found that this group of secondary metabolites displayed topoisomerase inhibitory activity, which implied that endophytic fungi from salt-tolerance plants might be one new reservoir for natural product chemistry in future.

\section{CONFLICT OF INTEREST}

The authors declare no conflict of interest.

\section{ACKNOWLEDGEMENTS}

We thank the National Natural Science Foundation of China (31670011, 81202452), Youth Fund of Shandong Province Natural Science (ZR2011CQ011) and Foundation of Taishan Medical University high-level cultivate project (2015GCC14) for financial support.

1 Kjer, J., Debbab, A., Aly, A.H. \& Proksch, P. Methods for isolation of marine-derived endophytic fungi and their bioactive secondary products. Nat. Protoc. 5, 479-490 (2010).

2 Debbab, A., Aly, A. H. \& Proksch, P. Mangrove derived fungal endophytes - a chemical and biological perception. Fungal Divers. 61, 1-27 (2013).

3 Bugni, T. S. \& Ireland, C. N. Marine-derived fungi: a chemically and biologically diverse group of microorganisms. Nat. Pro. Rep. 21, 143-163 (2004).

4 Luo, Y. C., Tian, L., Han, F. F. \& Li, Y. G. Identification of sea Bacterium B-9987 and test of its inhibition to some phytopathogens. Agrochemicals 47, 691-693 (2008). 
5 Xue, C. M., Tian, L., Xu, M. J., Deng, Z. W. \& Lin, W. H. A new 24-membered lactone and a new polyene $\delta$-lactone from the marine bacterium Bacillus marinus. J. Antibiot. 61, 668-674 (2008).

6 Zhang, D. J., Liu, R. F., Li, Y. G., Tao, L. M. \& Li, T. Two new antifungal cyclic lipopeptides from Bacillus marinus B-9987. Chem. Pharm. Bull. 58, 1630-1634 (2010).

7 Liu, R. F., Zhang, D. J., Tao, L. \& Tian, L. A new antifungal cyclic lipopeptide from Bacillus marinus B-9987. Helv. Chim. Acta 93, 2419-2425 (2010).

8 Zhao, K. F. Desalinization of saline soils by Suaeda salsa. Plant Soil 135 , 303-305 (1991).

9 Li, D. L., Li, X. M., Li, T. G., Dang, H. Y. \& Wang, B. G. Dioxopiperazine alkaloids produced by the marine mangrove derived endophytic fungus Eurotium rubrum. Helv. Chim. Acta 91, 1888-1893 (2008)

$10 \mathrm{Li}$, D. L. et al. Benzaldehyde derivatives from Eurotium rubrum, an endophytic fungus derived from the mangrove plant Hibiscus tiliaceus. Chem. Pharm. Bull. 56, 1282-1285 (2008).

$11 \mathrm{Li}$, D. L., Li, X. M. \& Wang, B. G. Natural anthraquinone derivatives from a marine mangrove plant-derived endophytic fungus Eurotium rubrum: structural elucidation and DPPH radical scavenging activity. J. Microbiol. Biotechnol. 19, 675-680 (2009).

12 Yan, H. J., Li, X. M., Li, C. S. \& Wang, B. G. Alkaloid and anthraquinone derivatives Produced by the marine-derived endophytic fungus Eurotium rubrum. Helv. Chim. Acta 95, 163-168 (2012).

13 Li, D. L., Li, X. M., Proksch, P. \& Wang, B. G. 7-O-Methylvariecolortide A, a new spirocyclic diketopiperazine alkaloid from a marine mangrove derived endophytic fungus Eurotium rubrum. Nat. Prod. Commun. 5, 1583-1586 (2010).
14 Kalidhar, S. B. Structural elucidation in anthraquinones using ${ }^{1} \mathrm{H}$ NMR glycosylation and alkylation shifts. Phytochemstry 28, 3459-3463 (1989).

15 Anke, H., Kolthoum, I. \& Laatsch, H. Metabolic products of microorganisms. 192. The anthraquinones of the Aspergillus glaucus group. II. Biological activity. Arch. Microbiol. 126, 231-236 (1980).

16 Jayasuriya, H., Koonchanok, N. M., Geahlen, R. L., McLaughlin, J. L. \& Chang, C. J. Emodin, a protein tyrosine kinase inhibitor from Polygonum cuspidatum. J. Nat. Prod. 55, 696-698 (1992).

17 Sun, P. et al. Structural and stereochemical studies of hydorxyanthranquinone derivatives from the endophytic fungus Coniothyrium sp. Chirality 25, 141-148 (2013).

18 Ikuko, O., Takenori, K., Yoel, K. \& Hiroshi, K. High-field FT NMR application of Mosher's method. The absolute configuration of marine terpenoids. J. Am. Chem. Soc. 113, 4092-4096 (1991).

19 Polavarapu, P. L. Renaissance in chiroptical spectroscopic methods for molecular structure determination. Chem. Rec. 7, 125-136 (2007).

20 Gaussian 09, Revision C.01, Gaussian, Inc., Wallingford, CT, USA, 2010 www. gaussian.com.

21 MOE2009.10, Chemical Computing Group Inc www.chemcomp.com.

22 Trisuwan, K. et al. Anthraquinone, cyclopentanone, and naphthoquinone derivatives from the sea fan-derived fungi Fusarium spp. PSU-F14 and PSU-F135. J. Nat. Prod. 73, 1507-1511 (2010).

23 Zheng, C. et al. Bioactive hydroanthraquinones and anthraquinone dimers from a soft coral-derived Alternaria sp. fungus. J. Nat. Prod. 75, 189-197 (2012).

24 Yang, K. et al. Antibacterial anthraquinone derivatives from a sea anemone-derived fungus Nigrospora sp. J. Nat. Prod. 75, 935-941 (2012).

Supplementary Information accompanies the paper on The Journal of Antibiotics website (http://www.nature.com/ja) 